\title{
Age-Specific Thyroid Internal Dose Estimation for Koreans
}

\author{
Tae-Eun Kwon ${ }^{1,2}$, Seokwon Yoon', Wi-Ho Ha', Yoonsun Chung'2, Young Woo Jin ${ }^{1}$ \\ ${ }^{1}$ National Radiation Emergency Medical Center, Korea Institute of Radiological and Medical Sciences, Seoul, Korea; ${ }^{2}$ Department of Nuclear Engineering, \\ Hanyang University, Seoul, Korea
}

\section{Original Research}

Received March 11, 2021

Revision June 17, 2021

Accepted June 22, 2021

Corresponding author:Tae-Eun Kwon

Laboratory of Health Physics, National Radiation Emergency Medical Center, Korea Institute of Radiological and Medical Sciences, 75 Nowon-ro, Nowon-gu, Seoul 01812, Korea E-mail: ktgrace@kirams.re.kr

(iD https://orcid.org/0000-0002-7252-4634

This is an open-access article distributed under the terms of the Creative Commons Attribution License (http://creativecommons.org/licenses/by-nc/4.0), which permits unrestricted use, distribution, and reproduction in any medium, provided the original work is properly cited.

Copyright $\odot 2021$ The Korean Association for Radiation Protection

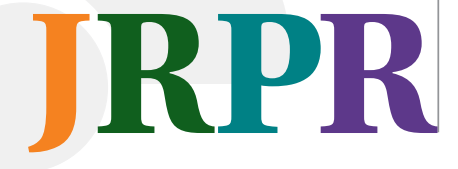

\section{Introduction}

The International Commission on Radiological Protection (ICRP) has recently developed a new reference iodine biokinetic model for adults [1] based on extensive humanbased data and arranged for the age-specific model [2] to be published. However, regional data provided in ICRP Publication 137 [3] show that the thyroidal uptake rate of iodine may be substantially higher than the ICRP reference uptake rate in regions with inadequate dietary iodine and substantially lower than the reference rate in regions with atypically high dietary iodine. Therefore, in order to predict the iodine biokinetics for a particular population, it is essential to consider the dietary iodine amount for that population. For South Koreans, one of the high-iodine-consuming populations, the mean daily iodine intake has been reported to range from $780 \mu \mathrm{g} \cdot \mathrm{d}^{-1}[4]$ to a few thou- 
sand $\mu \mathrm{g} \cdot \mathrm{d}^{-1}[5]$. For this reason, iodine biokinetic models have been developed specifically for South Koreans, reflecting the Korean-specific thyroid biokinetics, and a model for adult Koreans was proposed in a previous study [6]. In the development of the Korean model, it was concluded that transfer coefficients for thyroidal uptake rate, hormonal secretion rate, and leakage rate of thyroidal organic iodine as inorganic iodide were significantly different from those in ICRP reference model, and the Korean-specific values were determined to yield measurements of thyroidal iodine and physiological status of Korean adults (see Section 2.4 in [6]).

For a low dose exposure of a few $\mathrm{mSv}$, the use of ICRP reference data based on the ICRP reference model for Koreans may be reasonable and acceptable, particularly when simplicity and consistency of dose assessment are considered. However, when a high dose is predicted, applying the ICRP reference data to Koreans can result in a serious bias; for example, in the case of Radioactive Iodine Therapy (RAIT) with an administration of hundreds of $\mathrm{mCi}$ or a radiation emergency accompanied by an unwanted high dose exposure, the estimated thyroid absorbed doses based on ICRP reference data may significantly differ from actual doses received by Korean patients or victims.
Therefore, for more accurate and realistic dose estimations of Korean individuals including Korean infants and children, this study attempted to expand the adult Korean-specific iodine biokinetic model to other age groups-i.e., infants (100 days), 1, 5, 10, and 15 years, respectively-and to produce age-specific thyroid dose coefficients using derived thyroid mass data.

\section{Materials and Methods}

\section{Age-Specific Iodine Biokinetic Parameters for Koreans}

Since it is very difficult to directly measure iodine biokinetics in the immature human body, few investigations of the age-specific iodine biokinetics in Korea have been conducted; thus, available data for Korean infants and children are not sufficient for developing biokinetic models. The best way to develop the Korean age-specific model is to adopt the design principles used in the development of age-specific models for world population with the assumption that relative changes in iodine biokinetics with age for the world population are directly applicable to Koreans. Age-specific iodine models (Fig. 1) were recently developed by Leggett [2],

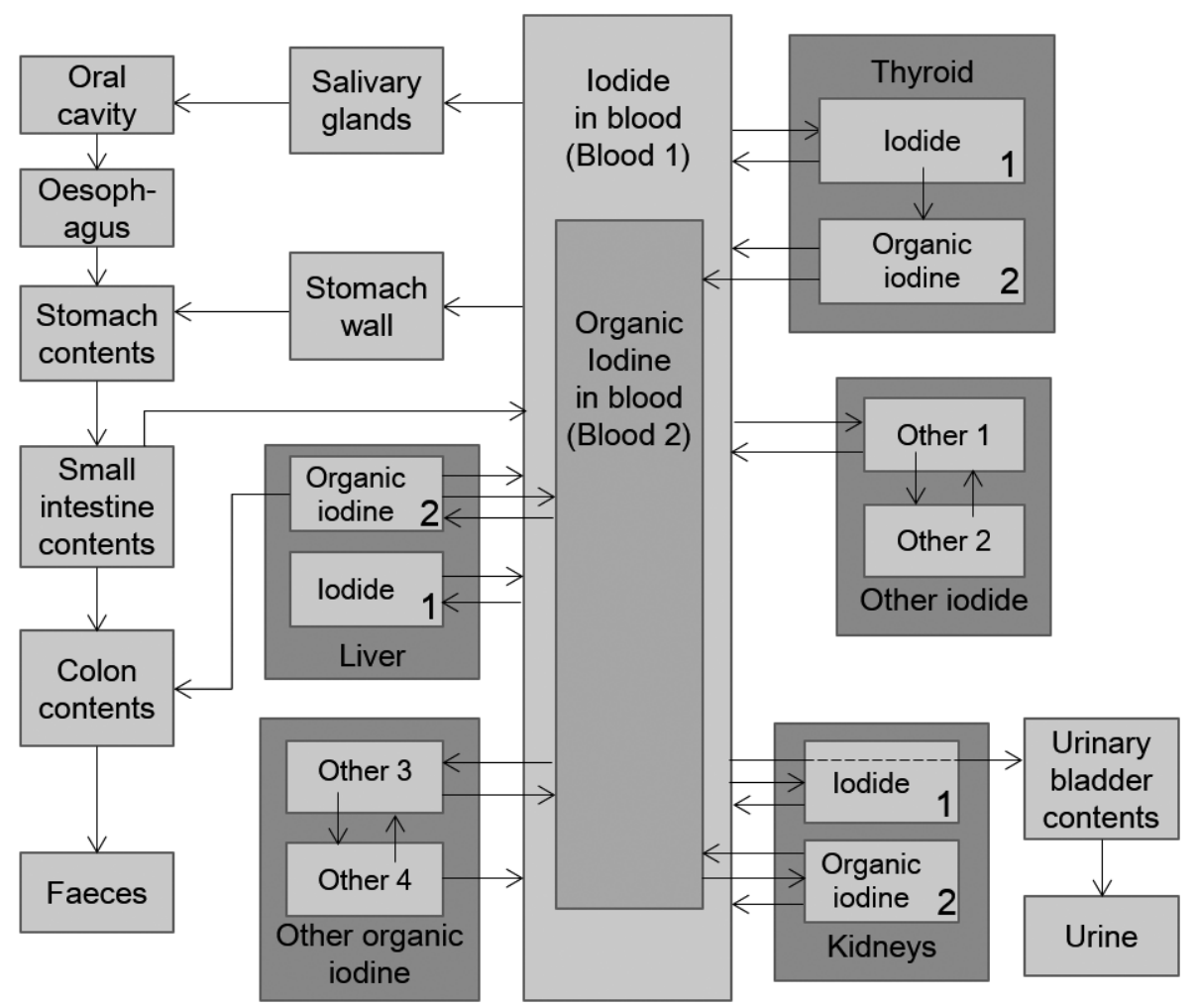

Fig. 1. Basic structure of the new biokinetic model for iodine provided in ICRP Publication 137 [3]. 
based on data on the biokinetics of iodine in the immature human body, and are being prepared for publication as ICRP reference models. Therefore, in the present study, the agespecific biokinetic parameters (i.e., transfer coefficients) were derived based on the values of Leggett's age-specific model and the Korean adult model.

In the development of Leggett's model [2], it was concluded that the following biokinetics of iodine showed an age dependence: (1) the thyroidal uptake of iodine, (2) the biological half-life of organic iodine in the thyroid, and (3) the biological half-life of extrathyroidal organic iodine. However, since the different thyroidal uptake fractions of ingested iodine were observed only in the first week or two of life, it did not affect the youngest age group (100 days). Therefore, in the Leggett's model [2], transfer coefficients representing the biological half-lives of intra- or extra-thyroidal organic iodine were regarded as age-specific, and the baseline values were determined based on measurement data for infants and children. The same approach was used in the present study. First, the age-specific turnover times of extra-thyroidal organic iodine discussed by Leggett [2] (i.e., 4, 4.5, 5, 5.5, and 6 days in infants, at ages $1,5,10$, and 15 years, respectively) and the ratios of these times to the corresponding time for adults (i.e., 7 days) were directly applied to Koreans. Because a turnover time of extra-thyroidal organic iodine in the ICRP adult model was not changed in the Korean adult model due to a lack of data for Koreans (see Section 2.3 in [6]), the transfer coefficients involved in the biokinetics of extra-thyroidal organic iodine were directly taken from the baseline values of Leggett's model [2]. However, for the biological half-life of thyroidal organic iodine showing a significant difference between the Korean adult model and the ICRP model, the baseline values proposed by Leggett [2] cannot be directly used. Therefore, the Korean age-specific biological half-lives were derived from the Korean adult value (i.e., 27 days) using the ratios obtained from Leggett's model [2]. Note that the transfer coefficient corresponding to the biological half-life of $T_{1 / 2}$, is $\ln 2 / T_{1 / 2}$. As addressed in the literature for Korean adult model development, another difference between the Korean and ICRP reference models regarding the biological half-life in the thyroid is that, in the Korean model, the organic iodine in the thyroid can be removed into blood, not only as an organic form of iodine but also as an inorganic form of iodide; this is expressed as the transfer from Thyroid 2 to the Blood 1 compartment. Therefore, transfer coefficients representing the biological half-life in the thyroid must be proper- ly apportioned to the Thyroid 2-to-Blood 1 rate and the Thyroid 2-to-Blood 2 rate. In the present study, the values corresponding to the age-specific biological half-lives for Koreans were separated into the two transfer coefficients with the assumption that the apportion ratio is equal to that determined in the Korean adult model (i.e., the ratio of "Thyroid 2-toBlood 1 rate" and "Thyroid 2-to-Blood 2 rate" is 0.43:0.57).

\section{Derivation of Age-Specific Thyroid Mass for Koreans}

The thyroid mass is reported to be dependent on not only physical parameters such as total body mass but also nutrition conditions such as dietary iodine intake; for example, the thyroid mass is substantially higher in populations with mild iodine deficiency than in populations with iodine sufficiency. The reference values of age-specific thyroid mass for the worldwide population were provided in ICRP Publication 89 [7], and the values for adult Koreans were reported elsewhere [8]. However, for Korean infants and children, agespecific thyroid masses have not been reported, and few relevant data are available. Although the International Atomic Energy Agency (IAEA) has provided the organ masses, including the thyroid, for reference Asian men [9] according to the five age groups, it is not appropriate to directly apply them to Koreans because there is a significant discrepancy between the values of adult thyroid masses quoted in the IAEA report ( $19 \mathrm{~g}$ for male, $17 \mathrm{~g}$ for female) and the values applicable to the Korean reference man ( $15 \mathrm{~g}$ for male, $12 \mathrm{~g}$ for female). Therefore, in the present study, the Korean agespecific thyroid masses were derived from the reference value for Korean adult male by using the ratios of age-specific values to the adult value; this is a similar approach to the one used for the determination of age-specific biokinetic parameters. To derive the reference thyroid masses including blood contents, age-dependent values for regional blood distribution provided by Wayson [10] were used.

\section{Thyroid Dose Coefficients Calculation}

Thyroid dose coefficients, $h_{T h}$, can be calculated from the following equation:

$$
h_{T h}(G y / B q)=\sum_{i} \tilde{a}(i, \tau) S(t h \leftarrow i)
$$

where $\tilde{a}(i, \tau)$ is the cumulative activity in the source region $i$ during the integration time $\tau$, and $S(t h \leftarrow i)$ is the S-value, which means the energy absorbed per unit mass of the target organ (i.e., the thyroid) per transformation of the iodine in 
source organ $i$. For the calculation of $\tilde{a}(i, \tau)$, the Korean biokinetic model for iodine coupled with the human respiratory tract model of ICRP Publication 66 [11] and the human alimentary tract model of ICRP Publication 100 [12] was calculated with first-order differential equations. For simplicity, changes of the transfer coefficients with an increase in age were not considered in the calculations of cumulative activities. The integration time $\tau$ is 50 years for adults, and the period from each of the specified pre-adult ages to 70 years for infants and children, respectively. The S-value is typically derived from the values of the absorbed fraction (AF) or the specific absorbed fraction (SAF), which are computed from computational anthropomorphic phantoms using a Monte Carlo simulation technique. For internal exposure to iodine, because the thyroid dose is predominantly attributable to self-irradiation of particles emitted from thyroidal iodine, the source organ for the S-value can be limited to the thyroid itself (i.e., $S(t h \leftarrow t h))$. The age-specific values for $S(t h \leftarrow t h)$ were derived from the values calculated by Zanzonico [13]. The values of $S(t h \longleftarrow t h)$ were by using the ratios of age-specific thyroid masses for Koreans to those used in the literature.

\section{Results and Discussion}

\section{Korean Age-Specific Biokinetic Parameters}

The derived Korean age-specific transfer coefficients are listed in Table 1. In accordance with the principle of Leggett's model [2], the leakage rate of thyroidal organic iodine (i.e., the Thyroid 2-to-Blood 1 rate and the Thyroid 2-to-Blood 2 rate) and the turnover rates of extra-thyroidal organic iodine are derived as age-specific values. In particular, the Blood

Table 1. Korean Age-Specific Biokinetic Parameters

\begin{tabular}{|c|c|c|c|c|c|c|c|c|}
\hline & \multirow{2}{*}{ From } & \multirow{2}{*}{ To } & \multicolumn{6}{|c|}{ Age group } \\
\hline & & & Infant (3 mo) & $1 \mathrm{yr}$ & $5 \mathrm{yr}$ & $10 \mathrm{yr}$ & $15 \mathrm{yr}$ & Adult \\
\hline \multirow[t]{5}{*}{ Intrathyroidal iodine } & Blood_1 & Thyroid_1 & 4.48 & 4.48 & 4.48 & 4.48 & 4.48 & 4.48 \\
\hline & Thyroid_1 & Thyroid_2 & 95 & 95 & 95 & 95 & 95 & 95 \\
\hline & Thyroid_1 & Blood_1 & 36 & 36 & 36 & 36 & 36 & 36 \\
\hline & Thyroid_2 & Blood_2 & 0.0773 & 0.0515 & 0.0258 & 0.0155 & 0.0119 & 0.0086 \\
\hline & Thyroid_2 & Blood_1 & 0.1537 & 0.1025 & 0.0512 & 0.0307 & 0.0237 & 0.0171 \\
\hline \multirow[t]{13}{*}{ Extrathyroidal inorganic iodide } & Blood_1 & UB-cont & 11.84 & 11.84 & 11.84 & 11.84 & 11.84 & 11.84 \\
\hline & Blood_1 & S-glands & 5.16 & 5.16 & 5.16 & 5.16 & 5.16 & 5.16 \\
\hline & Blood_1 & St-wall & 8.6 & 8.6 & 8.6 & 8.6 & 8.6 & 8.6 \\
\hline & Blood_1 & Kidneys_1 & 25 & 25 & 25 & 25 & 25 & 25 \\
\hline & Blood_1 & Liver_1 & 15 & 15 & 15 & 15 & 15 & 15 \\
\hline & Kidneys_1 & Blood_1 & 100 & 100 & 100 & 100 & 100 & 100 \\
\hline & Liver_1 & Blood_1 & 100 & 100 & 100 & 100 & 100 & 100 \\
\hline & S-glands & O-cavity & 50 & 50 & 50 & 50 & 50 & 50 \\
\hline & St-wall & St-cont & 50 & 50 & 50 & 50 & 50 & 50 \\
\hline & Blood_1 & Other_1 & 600 & 600 & 600 & 600 & 600 & 600 \\
\hline & Other_1 & Blood_1 & 330 & 330 & 330 & 330 & 330 & 330 \\
\hline & Other_1 & Other_2 & 35 & 35 & 35 & 35 & 35 & 35 \\
\hline & Other_2 & Other_1 & 56 & 56 & 56 & 56 & 56 & 56 \\
\hline \multirow[t]{12}{*}{ Extrathyroidal organic iodine } & Blood_2 & Other_3 & 26.30 & 23.30 & 21.00 & 19.10 & 17.50 & 15.00 \\
\hline & Other_3 & Blood_2 & 36.80 & 32.70 & 29.40 & 26.70 & 24.50 & 21.00 \\
\hline & Other_3 & Other_4 & 2.10 & 1.87 & 1.68 & 1.53 & 1.40 & 1.20 \\
\hline & Other_4 & Other_3 & 1.09 & 0.96 & 0.87 & 0.79 & 0.72 & 0.62 \\
\hline & Other_4 & Blood_1 & 0.25 & 0.22 & 0.20 & 0.18 & 0.16 & 0.14 \\
\hline & Blood_2 & Kidneys_2 & 6.30 & 5.60 & 5.04 & 4.58 & 4.20 & 3.60 \\
\hline & Kidneys_2 & Blood_2 & 36.80 & 32.70 & 29.40 & 26.70 & 24.50 & 21.00 \\
\hline & Kidneys_2 & Blood_1 & 0.25 & 0.22 & 0.20 & 0.18 & 0.16 & 0.14 \\
\hline & Blood_2 & Liver_2 & 36.80 & 32.70 & 29.40 & 26.70 & 24.50 & 21.00 \\
\hline & Liver_2 & Blood_2 & 36.80 & 32.70 & 29.40 & 26.70 & 24.50 & 21.00 \\
\hline & Liver_2 & Blood_1 & 0.25 & 0.22 & 0.20 & 0.18 & 0.16 & 0.14 \\
\hline & Liver_2 & RC-cont & 0.14 & 0.12 & 0.11 & 0.10 & 0.09 & 0.08 \\
\hline
\end{tabular}

S-glands, salivary glands; O-cavity, oral cavity; St-wall, stomach wall; St-cont, stomach content; RC-cont, right colon content. 
1-to-Thyroid 1 rate, Thyroid 2-to-Blood 1 rate, and Thyroid 2-to-Blood 2 rate represent Korean-specific values, which are different from the ICRP references, and the Blood 1-to-Thyroid 1 rate in the Korean adult model was directly adopted for the thyroid uptake rates in Korean infants and children.

\section{Biokinetic Model Prediction}

As examples, the thyroid retention function and the daily urinary excretion function, assuming no radioactive decay, for 5 years old predicted on the basis of the Korean model are compared with those predicted by other models in Fig. 2 . In addition to the results based on the Leggett's model [2], the predicted values based on the ICRP Publication 56 model (current ICRP age-specific model) [14] were drawn together to show the difference in the model prediction resulting from differences in model structures. Compared to the prediction of the ICRP Publication 56 model, the thyroid retention function predicted by the Korean model starts at higher values but remains at significantly lower values after 1 hour of iodine intake. This difference in the tendency of the two thyroid retention functions results from the difference in the model structures. As addressed in the literature discussed by Leggett [1], the new iodine biokinetic model structure depicts a faster thyroidal uptake of inorganic iodide but a rapid return to the blood after a shorter retention. On the other hand, compared to Leggett's model [2], the Korean model consistently predicts a substantially lower thyroidal uptake of iodine from iodine exposure. In addition, the decrease in thyroidal iodine after 1 day was also faster in the Korean model. These deviations from the predictions of the Leggett's model [2] can be explained in the same way as in the Korean

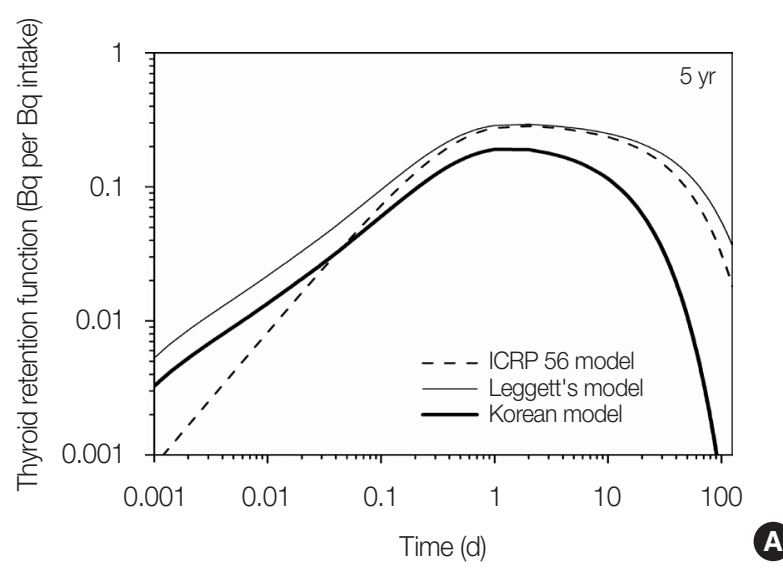

adult model development [6]. In brief, these differences result from the faster thyroid uptake rate of blood inorganic iodide and the shorter biological half-life in the thyroid.

It is natural that the Korean model predicts a much quicker excretion of urinary iodine in the early phase; however, after approximately 30 day, the trends in the respective curves are interchanged. Because urinary excretion is directly related to the inorganic iodide concentration in the blood, the difference in the daily urinary excretion of iodine can be explained by the inorganic iodide behavior. In the Korean model, a larger amount of inorganic iodide remains in the blood due to the lower uptake of thyroid in the early phase, but the decrease in inorganic iodide in blood might be faster due to the lower recycling of blood iodide. The differences described above were observed in an identical fashion, regardless of age. A more in-depth discussion can be found in a previous study on Korean adult model development [6].

Age-specific curves for thyroidal iodine and daily urinary excretion in Koreans are shown in Fig. 3. The thyroidal iodine peaks at about 0.18 after 1 day regardless of the age group and decreases depending on the age-specific biological half-life. The decrease in thyroidal iodine was fastest in infants with the shortest biological half-life. Therefore, it is natural that urinary excretion of iodine in the early phase is the greatest in infants.

\section{Age-Specific Thyroid Mass and S-Value for Koreans}

The derived age-specific thyroid masses for ICRP reference and for Koreans are shown in Table 2. The determined Korean thyroid masses were approximately $24 \%$ lower than the ICRP reference values, but comparable to or a little high-

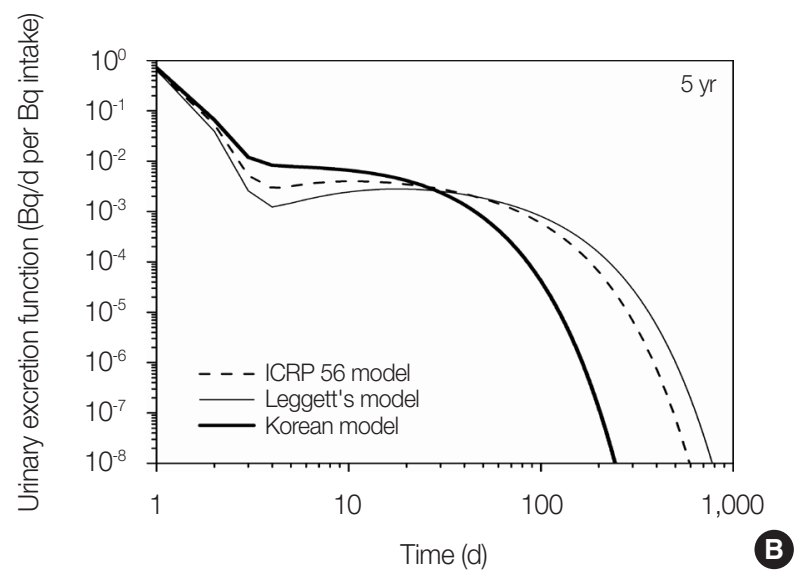

Fig. 2. Predicted thyroid retention functions (A) and daily urinary excretion functions (B) for 5 -year-old, based on the ICRP Publication 56 model [14], Leggett's model [2], and the Korean model (this study). 
er than the thyroid masses for Japanese infants and children $(\mathrm{n}=38,063)$ measured by ultrasound examination in the Fukushima Health Management Survey [15]. Although data were not available for the validation of all age-specific values, the thyroid mass for Korean newborns $(0.97 \mathrm{~g})$ seemed to be reasonable, considering the difference between the derived thyroid widths (i.e., sum of lengths for left and right lobes) for American fetuses (2.46 cm for 40 weeks [16]) and Korean fetuses (2.07 cm for 40 weeks [17]). Assuming that thyroid lengths for Korean fetuses are smaller as the same ratio as that applicable to thyroid width (i.e., $2.07 / 2.46=0.84$ ) and that thyroid thicknesses for Korean fetuses are equal to those

Table 2. Derived Korean Age-Specific Thyroid Masses

\begin{tabular}{lccccc}
\hline \multirow{2}{*}{ Age group } & \multicolumn{5}{c}{ Thyroid mass $(\mathrm{g})$} \\
\cline { 2 - 6 } & ICRP 89 & Asian & Japanese $^{\text {b) }}$ & Korean & Korean/ICRP 89 \\
\hline Newborn & 1.52 & - & 1.0 & 0.98 & 0.76 \\
$1 \mathrm{yr}$ & 1.99 & 2.3 & 1.3 & 1.28 & 0.72 \\
$5 \mathrm{yr}$ & 4.05 & 4.5 & 2.5 & 2.60 & 0.75 \\
$10 \mathrm{yr}$ & 9.18 & 8.4 & 4.6 & 5.89 & 0.74 \\
$15 \mathrm{yr}$ & 14.32 & 16 & 7.6 & 9.20 & 0.74 \\
Adult male & 23.36 & 19 & - & 15.00 & 0.75 \\
\hline
\end{tabular}

ICRP, International Commission on Radiological Protection.

${ }^{a} B$ Blood contents in thyroid were derived using age-dependent values for regional blood distribution provided by Wayson [10].

${ }^{b}$ Graphically extracted from data $(n=38,063)$ of the Fukushima Health Management Survey [15].

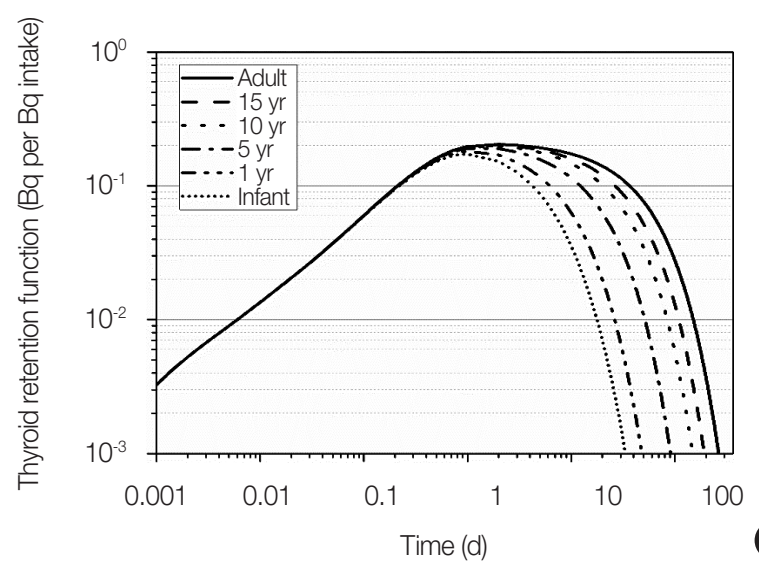

A

for American fetuses, the thyroid volumes for the Korean fetuses would be approximately $71 \%$ of those for the American fetuses. The age-specific S-values for thyroid self-irradiation for Koreans, derived by mass-correction based on the thyroid mass of Koreans, are presented in Table 3.

\section{Cumulative Activity in the Thyroid and Thyroid Dose Coefficients}

The ratios of the cumulative activities in the thyroid of injected iodine calculated using the Korean age-specific models, compared with those calculated using Leggett's model [2], are listed in Table 4. Due to the lower thyroidal uptake of iodine and the shorter biological half-life in Koreans, the values based on the Korean model were substantially lower (by 36\%-80\%) than those based on Leggett's model [2]. The differences were particularly striking for the longer-lived isotopes (e.g., ${ }^{125} \mathrm{I}$ and $\left.{ }^{129} \mathrm{I}\right)$. The larger differences for the longerlived isotopes result from the fact that the decrease in the thyroid of those iodine isotopes with a long physical half-life is predominantly determined by the rate of physiological clearance rather than the rate of radioactive decay. In contrast, for iodine isotopes with a short half-life, the biological differences have a lesser effect on the cumulative activity in the thyroid because significant fractions of those iodine isotopes are lost to radioactive decay before they can be absorbed by the thyroid or cleared from the thyroid on biologi-

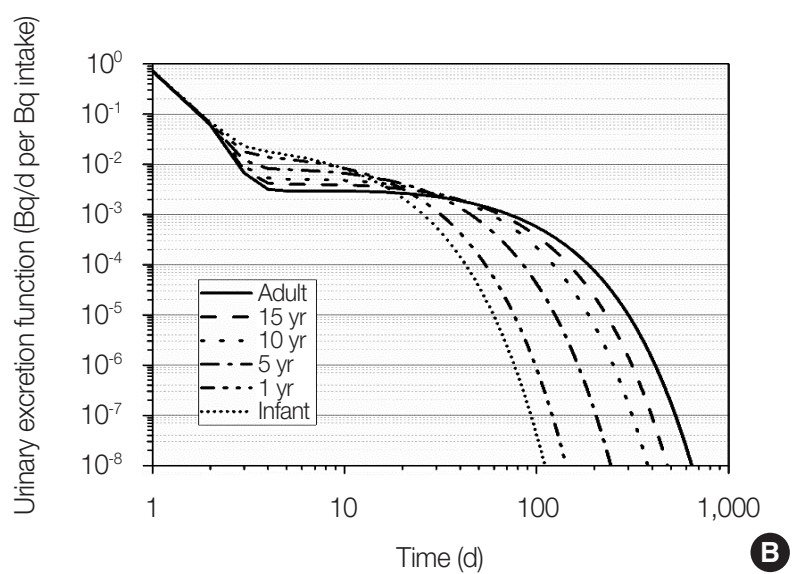

Fig. 3. Age-specific thyroid retention functions (A) and daily urinary excretion functions (B) for Koreans, assuming no radioactive decay.

Table 3. Derived Korean Age-Specific S-Values for Thyroid Self-Irradiation

\begin{tabular}{ccccccc}
\hline & \multicolumn{5}{c}{$S($ th $\leftarrow$ th) $(\mathrm{Sv} / \mathrm{Bq} \cdot \mathrm{s})$} \\
\cline { 2 - 7 } & Infant $(3 \mathrm{mo})$ & $1 \mathrm{yr}$ & $5 \mathrm{yr}$ & $10 \mathrm{yr}$ & $15 \mathrm{yr}$ & Adult \\
\hline${ }^{125}$ & $3.43 \times 10^{-12}$ & $2.85 \times 10^{-12}$ & $1.53 \times 10^{-12}$ & $6.91 \times 10^{-13}$ & $4.41 \times 10^{-13}$ & $3.00 \times 10^{-13}$ \\
${ }^{131}$ & $2.85 \times 10^{-11}$ & $2.37 \times 10^{-11}$ & $1.24 \times 10^{-11}$ & $5.34 \times 10^{-12}$ & $3.34 \times 10^{-12}$ & $2.20 \times 10^{-12}$ \\
\hline
\end{tabular}


Table 4. Comparison of Cumulative Activity in the Thyroid of Injected lodine Based on Leggett's Model [2] and the Korean Model

\begin{tabular}{llcccccc}
\hline \multirow{2}{*}{ Isotopes } & Half-life & \multicolumn{5}{c}{ Ratio of cumulative activity (Korean/Leggett) } \\
\cline { 3 - 7 } & & Infant $(3 \mathrm{mo})$ & $1 \mathrm{yr}$ & $5 \mathrm{yr}$ & $10 \mathrm{yr}$ & $15 \mathrm{yr}$ & Adult \\
\hline${ }^{122} \mid$ & $3.63 \mathrm{~min}$ & 0.62 & 0.62 & 0.62 & 0.62 & 0.62 & 0.62 \\
${ }^{124} \mid$ & $4.18 \mathrm{~d}$ & 0.44 & 0.49 & 0.56 & 0.60 & 0.62 & 0.64 \\
${ }^{125}$ & $59.4 \mathrm{~d}$ & 0.23 & 0.24 & 0.28 & 0.32 & 0.35 & 0.38 \\
${ }^{129}$ & $1.6 \times 10^{7} \mathrm{yr}$ & 0.20 & 0.20 & 0.20 & 0.20 & 0.20 & 0.20 \\
${ }^{131} \mid$ & $8.02 \mathrm{~d}$ & 0.36 & 0.41 & 0.49 & 0.55 & 0.57 & 0.60 \\
${ }^{132}$ & $2.3 \mathrm{~h}$ & 0.62 & 0.62 & 0.62 & 0.62 & 0.62 & 0.62 \\
${ }^{134}$ & $52.5 \mathrm{~min}$ & 0.63 & 0.63 & 0.63 & 0.63 & 0.63 & 0.63 \\
\hline
\end{tabular}

Table 5. Thyroid Dose Coefficients for Injected lodine Based on Leggett's Model [2] and the Korean Model

\begin{tabular}{|c|c|c|c|c|c|c|}
\hline & \multicolumn{6}{|c|}{ Thyroid dose coefficients (Gy/Bq) } \\
\hline & Infant (3 mo) & $1 \mathrm{yr}$ & $5 \mathrm{yr}$ & $10 \mathrm{yr}$ & $15 \mathrm{yr}$ & Adult \\
\hline \multicolumn{7}{|l|}{$125 \mid$} \\
\hline Leggett & $9.80 \times 10^{-7}$ & $1.20 \times 10^{-6}$ & $1.00 \times 10^{-6}$ & $6.10 \times 10^{-7}$ & $4.50 \times 10^{-7}$ & $3.30 \times 10^{-7}$ \\
\hline Korean & $3.20 \times 10^{-7}$ & $3.87 \times 10^{-7}$ & $3.83 \times 10^{-7}$ & $2.60 \times 10^{-7}$ & $2.01 \times 10^{-7}$ & $1.70 \times 10^{-7}$ \\
\hline Korean/Leggett ratio & 0.33 & 0.32 & 0.38 & 0.43 & 0.45 & 0.52 \\
\hline \multicolumn{7}{|l|}{${ }^{131} \mid$} \\
\hline Leggett & $3.60 \times 10^{-6}$ & $3.60 \times 10^{-6}$ & $2.20 \times 10^{-6}$ & $1.10 \times 10^{-6}$ & $7.10 \times 10^{-7}$ & $4.50 \times 10^{-7}$ \\
\hline Korean & $1.85 \times 10^{-6}$ & $1.99 \times 10^{-6}$ & $1.48 \times 10^{-6}$ & $7.67 \times 10^{-7}$ & $5.17 \times 10^{-7}$ & $3.65 \times 10^{-7}$ \\
\hline Korean/Leggett ratio & 0.51 & 0.55 & 0.67 & 0.70 & 0.73 & 0.81 \\
\hline
\end{tabular}

cal timescales.

As described previously, in the calculations of cumulative activities in the thyroid, the continuous changes of the transfer coefficients with age were not considered; however, this does not have a significant effect not only for short-lived iodine but also for longer-lived iodine due to the short biological half-life in the thyroid (i.e., 27 days for Koreans). For instance, the cumulative activities in the thyroid of injected ${ }^{129} \mathrm{I}$ $\left(T_{1 / 2}=1.6 \times 10^{7}\right.$ years) for infant ( 3 months) based on the ICRP Publication 56 model with considering and without considering the age-dependent change of transfer coefficient were $5.637 \times 10^{5}$ and $5.512 \times 10^{5} \mathrm{nt} / \mathrm{Bq}$, respectively.

In Table 5, the age-specific thyroid dose coefficients for injected ${ }^{125} \mathrm{I}$ and ${ }^{131} \mathrm{I}$ calculated using the Korean model were compared with those provided by Leggett [2]. Although the $24 \%$ lower target organ masses (i.e., thyroid masses) of Korean infants and children were predicted to increase the thyroid dose, the age-specific thyroid dose coefficients for Koreans were still noticeably lower than those of Leggett's model [2]. These differences in thyroid dose coefficients suggest that the thyroids of Korean infants, children, and adults would be less irradiated than predicted by ICRP reference age-specific models, for given quantities of radioiodine exposure. However, the use of the Korean age-specific bioki- netic model would not have a significant effect on the relative age-related variations in thyroid dose coefficients. For practical uses, dose coefficients for inhaled and ingested ${ }^{125} \mathrm{I}$ and ${ }^{131}$ I were calculated and provided in Supplementary Table S1 and Figs. S1-S6, together with corresponding thyroid retention functions and dose per content functions.

\section{Conclusion}

This study expanded the iodine biokinetic model for Korean adults to infants and children, by deriving age-specific biokinetic parameters. The model predictions and thyroid dose coefficients based on the Korean age-specific model showed noticeable deviations from the values proposed for the worldwide population, thus emphasizing the need to consider Korean-specific dose estimations for infants and children. However, the biokinetic parameters and thyroid masses of Korean infants and children are not perfect because they were not based on Korean measurement data but were indirectly derived. Fundamental studies on thyroid biokinetics and anatomy in the Korean immature body should be carried out to improve the accuracy of Korean agespecific biokinetic and dosimetric models. In addition, for more accurate calculations of age-specific biokinetic model, 
the continuous changes of the transfer coefficients with an increase in age should be considered.

\section{Conflict of Interest}

No potential conflict of interest relevant to this article was reported.

\section{Acknowledgements}

This study was supported by a grant of the Korea Institute of Radiological and Medical Sciences (KIRAMS), funded by the Nuclear Safety and Security Commission (NSSC), Republic of Korea (No. 50091-2021).

\section{Author Contribution}

Conceptualization: Kwon T. Data curation: Kwon T. Formal analysis: Kwon T. Funding acquisition: Jin YW. Methodology: Kwon T, Ha W, Chung Y. Visualization: Kwon T. Writing original draft: Kwon T. Writing - review \& editing: Kwon T, Ha W, Jin YW, Yoon S, Chung Y. Investigation: Kwon T, Ha W, Yoon S. Resources: Kwon T. Software: Kwon T. Supervision: Kwon T, Jin YW, Chung Y. Validation: Kwon T, Ha W, Jin YW, Chung Y.

\section{Supplementary Materials}

Supplementary materials can be found via https://doi.org/ 10.14407/jrpr.2021.00066.

\section{References}

1. Leggett RW. A physiological systems model for iodine for use in radiation protection. Radiat Res. 2010;174(4):496-516.

2. Leggett R. An age-specific biokinetic model for iodine. J Radiol Prot. 2017;37(4):864-882.

3. Paquet F, Bailey MR, Leggett RW, Lipsztein J, Marsh J, Fell TP, et al. ICRP Publication 137: Occupational Intakes of Radionuclides: Part 3. Ann ICRP. 2017;46(3-4):1-486.

4. Kim S, Kwon YS, Kim JY, Hong KH, Park YK. Association between iodine nutrition status and thyroid disease-related hormone in Korean adults: Korean National Health and Nutrition Examination Survey VI (2013-2015). Nutrients. 2019;11(11):2757.
5. Lee HS, Min H. Iodine intake and tolerable upper intake level of iodine for Koreans. Korean J Nutr. 2011;44(1):82-91.

6. Kwon TE, Chung Y, Jin YW. Korean-specific biokinetic model for iodine in radiological protection. J Radiol Prot. 2021;41(2):162178.

7. International Commission on Radiological Protection. Basic anatomical and physiological data for use in radiological protection: reference values: a report of age- and gender-related differences in the anatomical and physiological characteristics of reference individuals (ICRP Publication 89). Ottawa, Canada: International Commission on Radiological Protection; 2002.

8. Choi C, Yeom YS, Nguyen TT, Lee H, Han H, Shin B, et al. Korean anatomical reference data for adults for use in radiological protection. J Korean Phys Soc. 2018;72(1):183-191.

9. International Atomic Energy Agency. Compilation of anatomical, physiological and metabolic characteristics for reference Asian man. Wien, Austria: International Atomic Energy Agency; 1998.

10. Wayson MB. Computational internal dosimetry methods as applied to the University of Florida series of hybrid phantoms. Gainesville, FL: University of Florida; 2012.

11. International Commission on Radiological Protection. Human respiratory tract model for radiological protection (ICRP Publication 66). Ottawa, Canada: International Commission on Radiological Protection; 1994.

12. International Commission on Radiological Protection. Human alimentary tract model for radiological protection (ICRP Publication 100). Ottawa, Canada: International Commission on Radiological Protection; 2006.

13. Zanzonico PB. Age-dependent thyroid absorbed doses for radiobiologically significant radioisotopes of iodine. Health Phys. 2000;78(1):60-67.

14. International Commission on Radiological Protection. Age-dependent doses to members of the public from intake of radionuclides, Part 1 (ICRP Publication 56). Ottawa, Canada: International Commission on Radiological Protection; 1990.

15. Suzuki S, Midorikawa S, Fukushima T, Shimura H, Ohira T, Ohtsuru A, et al. Systematic determination of thyroid volume by ultrasound examination from infancy to adolescence in Japan: the Fukushima Health Management Survey. Endocr J. 2015;62(3): 261-268.

16. Bromley B, Frigoletto FD Jr, Cramer D, Osathanondh R, Benacerraf BR. The fetal thyroid: normal and abnormal sonographic measurements. J Ultrasound Med. 1992;11(1):25-28.

17. Ahn YC, Kim YH, Cho WS, Bae WK, Kim IY. Prenatal sonographic measurement of the fetal thyroid gland. J Korean Soc Med Ultrasound. 2001;20(1):65-69. 